\title{
Preliminary Study on Deep Integration of Theory Teaching and Practice Teaching for International Trade Practice Course in Higher Vocational Colleges
}

\author{
Qing Wu \\ Shanghai Aurora Vocational College, Shanghai, 201908, China
}

Keywords: theory teaching; practice teaching; integration

\begin{abstract}
Vocational education develops slowly in China. In addition to the reason of social concept, vocational colleges also should find out the reasons from themselves. The key is to improving teaching quality and promoting the public praise through characteristic teaching method and means. The author has been engaged in teaching International Trade for many years, and summarized some methods and means to combine theory teaching and practice teaching. Thus, this research starts from domestic and overseas researches. Five methods and means to integrate theory teaching and practice teaching of International Trade are summed up, including experimental training teaching, discipline competition teaching, online teaching, situational teaching, and integration of entrepreneurship education and professional education. Finally, the author hopes these methods and means can enlighten colleagues of vocational education.
\end{abstract}

\section{Introduction}

The report of the $19^{\text {th }}$ National Congress of the Communist Party of China proposes to "strive to let every child enjoy equal and high-quality education". It is the specific requirement of satisfying education in the new times. From the investment, the funds used for vocational education are not few. For the talent training scale of vocational education, per-capita investment is obviously small. Meanwhile, the limited increase of higher vocational education is mainly used for school building and training base construction, and practical training equipment purchase. The direct investment in the subject of higher vocational talent training - students and teachers is small. So, the motivation of higher vocational teachers to reform teaching methods and means and improve teaching quality is obviously insufficient.

Promotion of educational equality does not contradict against improvement of teaching quality. They are not the antagonistic relation, but the unified relation. Higher quality is the more superior fairness. The reform and development of higher vocational education should follow such thought. The above thought promoted the author to continuously explore teaching of International Trade, and summarized some effective teaching methods and means to combine theory teaching and practice teaching.

\section{Research Scheme of Deeply Integrating Theory Teaching and Practice Teaching of International Trade Practice}

\subsection{Literature Review}

There are very few relevant domestic and overseas researches. I learned through looking up relevant literatures that, Pro. Wang Wuyi from School of Business in Anhui University of Technology indicated in Teaching Reform Practice Analysis of International Trade Practice and Teaching Scheme Research that, the exploration of teaching content, practice teaching and teaching method in teaching practice accumulated experience for the teaching scheme of this course. Starting from cultivating high-quality talents with strong innovation ability, the whole scheme of course teaching should be good integration of classroom teaching, operation practice, textbook writing, case 
and software programming, heuristic education and examination.

In Exploration of "Practice-oriented" International Trade Practice Teaching Reform - Based on Practice Teaching Experience of School of Economics and Management in North China University of Technology, Prof. Jiang Yanshu from School of Economics and Management in North China University of Technology expounded practice-oriented international trade practice teaching reform is the objective need of cultivating applied talents and also the internal requirement of international trade practice course. To reach knowledge objective, ability objective and quality objective of international trade practice teaching, international trade practice teaching method system should be reformed and innovate. Practice orientation is the only way of international trade practice teaching reform, and also the development direction of international trade practice.

In Discussion on Practice Teaching Mode of International Trade Practice - "Learning from Doing”, Ding Xiufei from Beijing Normal University proposed that, International Trade Practice is a core course of international economic trade major with strong practicalness. Dewey's "Learning from Doing” practice teaching concept should be introduced in International Trade Practice. The trade terms were taken for example to discuss practice teaching mode of International Trade Practice by combining "five steps in thinking", in the hope of effectively promoting practical operation ability of international trade students.

The unique academic value and application value of existing researches on this topic mainly lie in the following: based on the above literatures, some scholars have studied practice teaching and theory teaching of international business courses, but the researches on deep integration of the two are few. Thus, this research expects to break through and innovate for deep integration of the two.

\subsection{Definition of Core Concept}

Practice teaching: it is an effective way to consolidate theoretical knowledge and deepen theoretical knowledge, an important link to cultivate high-quality talents with innovation awareness and also an important platform to connect theory with practice, cultivate students to grasp scientific method and improve operation ability. Besides, it can help students improve their accomplishment and form correct values.

International business practice teaching: the author considers the training room and enterprise practice base should be fully utilized to let students practice practical job skills on the basis of learning certain theory so as to reach the objective of grasping practical ability. Meanwhile, cross-border e-commerce may be combined for practice teaching.

Teaching reform: in a broad sense, it refers to education reform, including the reform of national education system; in a narrow sense, it refers to school teaching reform, including reform of teaching method, teaching means and teaching mode. Here, it refers to school teaching reform.

\subsection{Research Significance and Research Value}

The research significance of this topic, unique academic value and application value of existing researches lie in the following: based on the above literatures, some scholars have studied practice teaching and theory teaching of international business courses, but the researches on deep integration of the two are few. Thus, this research expects to break through and innovate for deep integration of the two. For example, many higher vocational colleges set cross-border e-commerce direction for international business major recently, which reflects the deep integration of theory teaching and practice teaching. International trade has turned to online trade from traditional offline trade. Online trade and offline trade have been integrated deeply. To adapt to such change, more e-commerce trainings should be integrated in theory teaching to let students directly operate on the training room and really reach deep integration of theory and practice teaching. Yiwu Industrial and Commercial College takes the lead in practice teaching of cross-border e-commerce. It deserves our study, but we also should notice that theory teaching of the college is insufficient. After all, higher vocational college is not the training school. It is necessary to properly infuse theory education for students and cultivate their good thinking habit and method. 


\section{Methods to Deeply Integrate Theory Teaching and Practice Teaching of International Trade Practice}

\subsection{Experimental training teaching}

The key to experimental training teaching of International Trade Practice is to provide an open teaching experiment platform for students and teachers. The platform pays equal attention to learning and practice. On this platform, teachers and students should form open and interactive relations. Through the interactive teaching mode, students can know students' operation situation and knowledge mastery level in time.

In the interactive teaching mode, students often exchange, communicate and share information resources, solve the problems and jointly complete the teaching tasks so as to form the interactive interpersonal relationship.

The development and improvement of teaching mode need continuous practice test. We take Mosoink Cloud Class for example. It supports computer, mobile phone and ipad. The teacher gains course invitation code through registering the course. After students download Mosoink Cloud Class APP, they register and input the invitation code to add in the mobile classroom. In the course of International Trade Practice, the teacher can organize course teaching, check students' learning schedule, organize the test and management students' scores through teaching management system of Mosoink Cloud Class. Students can check personal information and learning schedule, gain the latest teaching information. Manage their classroom notes and check the test result through the system.

The author once tried Mosoink Cloud Class and felt the technology is not mature enough. But it is helpful for checking work attendance, doing exercise, commenting the exercise and evaluating the exercise. Many teachers apply computer in class, so they have to upload PPT courseware to the platform and connect the network. This process is relatively tedious. Besides, if the answers to cases and questions are prepared in advance on the courseware, all answers must be deleted for the version for students. Moreover, the general video uploaded on Mosoink Cloud Class cannot be watched by students, and only the video of mp4 format can be viewed.

Table 1. Exercise summarization (excerpts)

\begin{tabular}{|c|c|c|c|c|c|c|c|c|}
\hline No. & Question (text) & Type & Score & $\begin{array}{l}\text { Correct } \\
\text { answer }\end{array}$ & $\begin{array}{l}\text { Correct } \\
\text { rate }\end{array}$ & Option & Option content & $\begin{array}{c}\text { Selection } \\
\text { rate }\end{array}$ \\
\hline \multirow{5}{*}{1} & \multirow{5}{*}{$\begin{array}{l}\text { What are the principles for small and } \\
\text { medium enterprises to choose the } \\
\text { channel of distribution? (\&nbsp;) }\end{array}$} & \multirow{5}{*}{$\begin{array}{l}\text { multiple } \\
\text { choice }\end{array}$} & \multirow{5}{*}{3} & \multirow{5}{*}{ A,B,D } & \multirow{5}{*}{$9.68 \%$} & A & $\begin{array}{l}\text { Economic benefit of } \\
\text { channel }\end{array}$ & $83.87 \%$ \\
\hline & & & & & & B & Chanel controllability & $67.74 \%$ \\
\hline & & & & & & C & Channel availability & $80.65 \%$ \\
\hline & & & & & & $\mathrm{D}$ & $\begin{array}{l}\text { Channel adaptation } \\
\text { \&nbsp; }\end{array}$ & $70.97 \%$ \\
\hline & & & & & & $\mathrm{E}$ & Channel cooperation & $64.52 \%$ \\
\hline \multirow{5}{*}{2} & \multirow{5}{*}{$\begin{array}{l}\text { Which are tangible products? } \\
\text { (\&nbsp;) }\end{array}$} & \multirow{5}{*}{$\begin{array}{l}\text { multiple } \\
\text { choice }\end{array}$} & \multirow{5}{*}{3} & \multirow{5}{*}{ B,C,D } & \multirow{5}{*}{$48.39 \%$} & A & Installation \&nbsp; & $25.81 \%$ \\
\hline & & & & & & B & Packaging & $100.00 \%$ \\
\hline & & & & & & $\mathrm{C}$ & Style & $87.10 \%$ \\
\hline & & & & & & $\mathrm{D}$ & Quality & $77.42 \%$ \\
\hline & & & & & & $\mathrm{E}$ & Interest & $6.45 \%$ \\
\hline \multirow{5}{*}{3} & \multirow{5}{*}{$\begin{array}{l}\text { Which are the marketing features of } \\
\text { small and medium enterprises? } \\
\text { (\&nbsp;) }\end{array}$} & \multirow{5}{*}{$\begin{array}{l}\text { multiple } \\
\text { choice }\end{array}$} & \multirow{5}{*}{3} & \multirow{5}{*}{ A,B,C,D,E } & \multirow{5}{*}{$32.26 \%$} & A & $\begin{array}{l}\text { Strong market } \\
\text { adaptation }\end{array}$ & $77.42 \%$ \\
\hline & & & & & & B & $\begin{array}{l}\text { Strong product } \\
\text { innovation ability }\end{array}$ & $74.19 \%$ \\
\hline & & & & & & $\mathrm{C}$ & $\begin{array}{l}\text { Weak market } \\
\text { competitiveness }\end{array}$ & $58.06 \%$ \\
\hline & & & & & & $\mathrm{D}$ & $\begin{array}{l}\text { Fund shortage, slack } \\
\text { promotion }\end{array}$ & $61.29 \%$ \\
\hline & & & & & & $\mathrm{E}$ & $\begin{array}{l}\text { Lack of marketing } \\
\text { talents }\end{array}$ & $67.74 \%$ \\
\hline
\end{tabular}


But, Mosoink Cloud Class Platform is helpful for the activity about exercise. The teacher may type in exercises and set the correct answers and commands of exercise times on the platform in advance. The teacher can let students do exercises through the command of "issue activity". Exercise time limit may also be set. Or, the time is controlled by the command of: end activity". Then, "student test paper", "test report" and "summarization and details" may be downloaded through Roshal Archive with the command of "export data". Then, the teacher can comment the exercise and ask question in classroom. Meanwhile, the score of every student, correct rate of every question and correct rate of every option can be seen. After using this function, I felt the correct is very good. The only defect is that only single choice and multiple choices can be exercised. Other exercises can only be conducted in PPT courseware or through other ways. I hope the technology developer can improve it gradually. The author directly copied the exercise of three multiple choices from "summarization and details", as shown in Table 1.

\subsection{Online teaching}

Compared with traditional classroom environment, educational information in online learning environment has the advantages of richness, diversity and sharing. Since knowledge content in online learning environment can be expressed through voice, picture, animation and image (obviously different from traditional text and charts), students can more easily arouse their interest in the online learning environment. Online learning environment makes the exchange of learners smoother. Students and teachers can discuss the problems through real-time or non-real-time tools such as phone, videoconferencing and email. In the online environment, all kinds of educational information resources form rich information. These resources can be shared through the server connection. Therefore, collaborative learning rather than individual learning is achieved under online learning environment. Through collaborative learning, the knowledge can be deepened.

The teaching in the online learning environment lacks face-to-face exchange between teachers and students. It is very important to establish the communication platform for teachers and students. The real-time or non-real-time communication platform can be used to solve the problems, expand the view and enhance the deep integration effect of theory teaching and practice teaching.

\subsection{Integration of entrepreneurship education and professional education}

The integration of theory and practice cannot be separated from entrepreneurship education. The integration of entrepreneurship education in professional education will cultivate students' learning interest and promote teaching quality.

The new generation of teaching content system including entrepreneurship education should be constructed to organically combine entrepreneurship education and international trade teaching. Firstly, it is required to modify the course outline, add entrepreneurship education link in the outline, bring it in the required course and encourage students to take active part in entrepreneurship course study. Secondly, it is required to revise relevant course textbooks, and introduce entrepreneurship knowledge in the textbooks. International Trade is a course with strong practicalness, so it has strong entrepreneurship potential. In textbook selection, the teaching materials with entrepreneurship content or entrepreneurship theme may be considered. The teachers should be encouraged to write the textbooks which combine professional education and entrepreneurship education to better serve for teaching. Finally, teachers should effectively link professional education and entrepreneurship education in teaching process and have entrepreneurship education while teaching professional knowledge. Teachers should combine current social development trend to expand the course content, such as adding cross-border e-commerce and special topic of Shanghai Free Trade Zone in International Trade teaching, so as to cultivate students' entrepreneurship thought and construct a complete teaching system.

After entrepreneurship education is combined with professional education, corresponding assessment and evaluation scheme should be adjusted. This may refer to the evaluation scheme of International Trade in the colleges of Wenzhou. The evaluation standard for students is to apply professional knowledge to start up business. Every student may be required to set up online stores on 
dhgate.com for international trade. The teacher can overall evaluate students' practical ability according to turnover, customer flow and operating profit when the course ends. (3)

\section{Summary}

However, we must state that, except the above five methods, discipline competition teaching method and situational teaching method are also the methods to integrate theory teaching and practice teaching for International Trade. In practice, they are not separate, and several methods may be combined. For example, experimental training teaching and online learning may be combined. Or, discipline competition teaching method and situational teaching method may be combined. We need to innovatively use various methods to reach the best effect of deep integration of theory teaching and practice teaching for International Trade.

\section{References}

[1] Li Yongsheng, higher vocational education reform cannot "ignore the human factor and see only the material factor”, Liberation Daily, 2018.3.27 (10).

[2] Guo Xiaoying, Zhao Xinfeng, Exploration on Experimental Curriculum Teaching for International Trade Practice under Open Online Teaching Perspective , Liu Xiao Jun et al., Research and Practice of International Economics and Trade, Tianjin: Nankai University Press, 2017. 153.

[3] Wang Xin, Wang Yujing, On Effective Ways to Integrate Entrepreneurship Education in Professional Education of International Economics and Trade in Local Colleges, Liu Xiaojun et al, Research and Practice of International Economics and Trade, Tianjin: Nankai University Press, 2017. 192-193. 